\title{
Role of Actions of Calcium Antagonists on Efferent Arterioles - with Special References to Glomerular Hypertension
}

\author{
Koichi Hayashi Yuri Ozawa Keiji Fujiwara Shu Wakino Hiroo Kumagai \\ Takao Saruta
}

Department of Internal Medicine, School of Medicine, Keio University, Tokyo, Japan

\section{Key Words}

Afferent arteriole Efferent arteriole $\cdot$ Calcium antagonists $\cdot$ Renal microcirculation .

Voltage-dependent calcium channels - Renal disease •

Efonidipine $\cdot$ Mibefradil $\cdot$ Hypertension

\begin{abstract}
Although calcium antagonists are used as a first-line antihypertensive agent, controversy attends the renal microvascular effects of calcium antagonists. Since calcium antagonists elicit predominant vasodilation of the afferent arteriole, they might ostensibly aggravate glomerular hypertension. Recently, novel types of calcium antagonists have been developed, some of which are reported to dilate efferent as well as afferent arterioles. The present review attempted to characterize the renal microvascular action of calcium antagonists, and evaluated the consequences of renal injury following the treatment with these antagonists. In contrast to predominant afferent arteriolar action of conventional calcium antagonists (e.g. nifedipine, nicardipine, amlodipine and diltiazem), novel antagonists (e.g. manidipine, nilvadipine, benidipine and efonidipine) potently dilated both afferent and efferent arterioles. The vasodilator action on efferent arterioles appears to be mediated in part by the blockade of T-type calcium channels, particularly
\end{abstract}

\section{KARGER}

Fax +41613061234

E-Mail karger@karger.ch

www.karger.com
(C) 2003 S. Karger AG, Basel

0250-8095/03/0234-0229\$19.50/0

Accessible online at:

www.karger.com/ajn through the inhibition of the intracellular calcium release mechanism. The comparison of the anti-proteinuric action of calcium antagonists in subtotally nephrectomized rats showed that efonidipine and enalapril, both possessing vasodilator action on efferent arterioles, exerted more prominent action than other calcium antagonists. Finally, in patients with chronic renal disease, a 48-week treatment with efonidipine reduced proteinuria, and this effect was seen even when the mean arterial blood pressure failed to reach below $100 \mathrm{~mm} \mathrm{Hg}$. In conclusion, although calcium antagonists potently inhibit afferent arteriolar constriction, efferent arteriolar responses to antagonists used. These divergent actions of these agents on the efferent arteriole may alter differently the glomerular hemodynamics, and could affect the final outcome of underlying renal diseases.

Copyright @ 2003 S. Karger AG, Basel

\section{Introduction}

Hypertension causes renal injury that eventually progresses to end-stage renal failure. To minimize the hypertension-induced renal damage, numerous antihypertensive agents have been developed, including calcium antagonists, angiotensin-converting enzyme inhibitors these agents vary, depending on the types of calcium

Koichi Hayashi, MD, PhD

Department of Internal Medicine, School of Medicine, Keio University

35 Shinanomachi, Shinjuku-ku

Tokyo 160-8582 (Japan)

Tel. +81 35363 3796, Fax +8133359 2745, E-Mail khayashi@sc.itc.keio.ac.jp 
Table 1. Effect of calcium antagonists on renal function

\begin{tabular}{|c|c|c|c|c|c|c|}
\hline $\begin{array}{l}\text { Calcium } \\
\text { antagonists }\end{array}$ & Species & $\mathrm{BP}$ & $\mathrm{RPF}$ & GFR & $\mathrm{FF}$ & Ref. \\
\hline \multirow[t]{5}{*}{ Nifedipine } & dog, i.a. & $\rightarrow$ & $\uparrow$ & $\uparrow$ & $\uparrow$ & 22 \\
\hline & dog, i.a. & $\downarrow$ & $\uparrow$ & $\uparrow$ & $\uparrow$ & 23 \\
\hline & dog, i.a. & $\downarrow$ & $\rightarrow$ & $\rightarrow$ & $\nearrow$ & 24 \\
\hline & human, i.v. & $\rightarrow$ & $\rightarrow$ & $\rightarrow$ & $\rightarrow$ & 25 \\
\hline & human (HT), i.v. & $\rightarrow$ & $\uparrow$ & $\uparrow$ & $\rightarrow$ & 25 \\
\hline \multirow[t]{2}{*}{ Nicardipine } & dog, i.a. & $\downarrow$ & $\uparrow$ & $\uparrow$ & $\uparrow$ & 26 \\
\hline & human (HT), i.v. & $\downarrow$ & $\uparrow$ & $\rightarrow$ & $\rightarrow$ & 27 \\
\hline Nitrendipine & human, p.o. & $\rightarrow$ & $\rightarrow$ & $\rightarrow$ & $\rightarrow$ & 28 \\
\hline Nisoldipine & rat, in vitro & $\rightarrow(\mathrm{RPP})$ & $\uparrow$ & $\uparrow$ & $\uparrow$ & 29 \\
\hline \multirow[t]{3}{*}{ Verapamil } & dog, i.a. & $\downarrow$ & $\uparrow$ & $\uparrow$ & $\nearrow$ & 30 \\
\hline & dog, i.a. & $\rightarrow$ & $\uparrow$ & $\uparrow$ & $\uparrow$ & 24 \\
\hline & dog, i.a. & $\downarrow$ & $\uparrow$ & $\rightarrow$ & $\rightarrow$ & 22 \\
\hline \multirow[t]{4}{*}{ Diltiazem } & dog, i.a. & $\rightarrow$ & $\uparrow$ & $\uparrow$ & $?$ & 31 \\
\hline & rat, i.v. & $\downarrow$ & $\rightarrow$ & $\uparrow$ & $\rightarrow$ & 32 \\
\hline & human (HT), p.o. & $\downarrow$ & $\uparrow$ & $\uparrow$ & $\rightarrow$ & 33 \\
\hline & rat, in vitro & $\rightarrow(\mathrm{RPP})$ & $\uparrow$ & $\uparrow$ & $\uparrow$ & 34 \\
\hline Amlodipine & rat, in vitro & $\rightarrow(\mathrm{RPP})$ & $\uparrow$ & $\uparrow$ & $\uparrow$ & 35 \\
\hline Manidipine & human (HT), i.v. & $\rightarrow$ & $\uparrow$ & 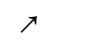 & $\downarrow$ & 36 \\
\hline Nilvadipine & SHR, i.v. & $\downarrow$ & $\uparrow$ & $\rightarrow$ & $\downarrow$ & 37 \\
\hline Efonidipine & SHR, i.v. & $\rightarrow(\mathrm{RPP})$ & $\uparrow$ & $\uparrow$ & $\downarrow$ & 38 \\
\hline
\end{tabular}

i.a. = Intra-renal arterial infusion; i.v. = intravenous; p.o. = oral; $\mathrm{BP}=$ blood pressure; $\mathrm{RPF}=$ renal plasma flow; GFR = glomerular filtration rate; $\mathrm{FF}=$ filtration fraction; $\mathrm{HT}=$ hypertension; RPP = renal perfusion pressure; $\uparrow=$ increase; $\downarrow=$ decrease; $\rightarrow=$ no change; $\nearrow=$ tend to increase.
(ACE-I), and angiotensin receptor antagonists (ARB). Indeed, calcium antagonists are widely used as a first-line antihypertensive agent with modest adverse effects. These agents are reported to preserve or even increase renal blood flow in the face of reduction in systemic blood pressure [1], suggesting a relatively renal selective action of these agents. Several lines of recent investigations have documented that within the renal vasculature, calcium antagonists cause a preferential dilation of the afferent arteriole, with only modest action on the efferent arteriole [2-4]. These effects are in contrast to those induced by ACE-I and ARB, which are documented to elicit predominant vasodilation of the efferent arteriole, ameliorate glomerular hypertension, and afford renal protection $[5,6]$. Thus, it is inferred that whereas the depressor action of the calcium antagonist favors an attenuation of glomerular hypertension and the subsequent renal protection [710], the predominant activity of this agent on preglomerular vessels might cause glomerular hypertension that could finally be associated with the progression of renal diseases [11-14]. Unlike the conventional types of calcium antagonists, however, novel types of these agents, including manidipine and efonidipine, are reported to dilate both afferent and efferent arterioles [15-21]. It remains undetermined whether these ostensibly beneficial effects may actually offer renal protective effect and influence the outcome of renal diseases. Thus, it appears of extreme importance to characterize the renal pre- and postglomerular vascular action of the calcium antagonist, from which we could extrapolate the status of the glomerular capillary pressure.

In this review, we survey the effects of a variety of calcium antagonists on the vascular tone of renal afferent and efferent arterioles. Furthermore, the long-term effect of the calcium antagonist on the renal function is also summarized.

\section{Effect of Calcium Antagonists on Renal Function}

The renal microvascular effect of calcium antagonists is greatly influenced by the underlying tone of the renal vasculature. Furthermore, the action of calcium antagonists varies depending on the agents used (table 1) [2238].

Heller et al. [22] and Dietz et al. [24] reported that when administered into anesthetized dogs, nifedipine caused a greater increase in glomerular filtration rate 
(GFR) than that in renal plasma flow (RPF), resulting in elevated filtration fraction. Furthermore, other calcium antagonists including nicardipine [26] and verapamil [24, 30] are reported to increase filtration fraction, suggesting predominant action on the afferent arteriole. In contrast, nicardipine [27] and diltiazem [33] are reported to have no effect on filtration fraction.

In the in vivo settings described above, however, systemic blood pressure was decreased, which may affect the glomerular perfusion pressure. To eliminate the pressureinduced changes in vascular tone, Loutzenhiser et al. [3, $29,34,35,39,40$ ] used the isolated perfused rat kidney model. This model allows constant renal perfusion pressure, whereby the myogenic tone of renal microvessels is unaltered. In a series of experiments, they found that under angiotensin II- or norepinephrine-induced vasoconstrictor tone, calcium antagonists including nifedipine, nisoldipine, diltiazem, and amlodipine caused greater increases in GFR than those in RPF, resulting in exaggerated increases in filtration fraction. Collectively, these observations again support the formulation that the calcium antagonist acts predominantly on the renal preglomerular vessels.

In contrast, when administered in normotensive subjects, calcium antagonists appear to cause only modest action on renal hemodynamics [25, 28]. These observed results may bear on the issue that calcium antagonists inhibit the calcium channels activated by vasoconstrictor stimuli, but have little effect on unstimulated vessels.

Although a large amount of investigations suggest that calcium antagonists cause predominant action on preglomerular vessels, a growing body of evidence has been accumulated demonstrating that certain types of these agents may affect postglomerular as well as preglomerular vessels (table 1). Takabatake et al. [36] found that the intravenous administration of manidipine caused a greater increase in RPF than that in GFR in spontaneously hypertensive rats (SHR), resulting in decreased filtration fraction. Furthermore, nilvadipine is reported to increase RPF without any changes in GFR in humans [41]. Finally, Yokoyama et al. [38] reported that efonidipine potently increased RPF more markedly than GFR, causing a decrease in filtration fraction. Collectively, the observations obtained in vivo strongly suggest that these calcium antagonists decrease efferent arteriolar resistance.

\section{Direct in vivo and in vitro Observations of the Renal}

\section{Microcirculation}

The predominant influence of conventional types of calcium antagonists on GFR suggests that these agents antagonize preglomerular vasoconstriction. Indeed, Kimura et al. [42] suggested that nicardipine elicited preferential reduction in afferent arteriolar resistance in hypertensive patients, using renal function curves. Recent development of renal physiology enables us to observe renal microvessels more directly [43-50]. These include (a) micropuncture technique; (b) isolated renal microvessels; (c) blood perfused juxtamedullary nephrons; (d) in vivo hydronephrotic kidneys; (e) isolated perfused hydronephrotic kidneys, and (f) intravital pencil-type CCD videomicroscopic technique.

Direct visualization of the renal microcirculation more substantively supports a preferential action of the calcium antagonist on the afferent arteriole. Casellas and Navar [47] developed an in vitro technique that allows direct visualization of the juxtamedullary nephron circulation. In their experiments, both verapamil and diltiazem potently inhibited the afferent arteriolar vasoconstriction, whereas efferent arterioles were relatively refractory to the vasodilator action of these agents [2]. Similarly, Ito et al. $[45,46]$ succeeded in isolation of the renal afferent and efferent arterioles, with an attached glomerulus and a thick ascending limb of Henle loop. Again, nifedipine predominantly dilated the afferent arteriole [21]. Fleming et al. [4] also demonstrated that nifedipine caused predominant afferent arteriolar dilation in the hydronephrotic kidney model in vivo.

Loutzenhiser and Epstein developed a model of the isolated perfused hydronephrotic kidney that facilitates direct observation of the renal microvasculature under defined in vitro conditions [3, 8, 9, 15-18, 20, 49, 51]. This experimental model allows constant renal perfusion pressure, thereby facilitating more direct observation on the changes in non-myogenic vascular tone. Using this model, we demonstrated that not only dihydropyridineclass (e.g. nifedipine, nicardipine, and amlodipine), but also benzothiazepine-class (e.g. diltiazem) calcium antagonists caused predominant vasodilation of the afferent arteriole, with only modest action on the efferent arteriole [15] (fig. 1). This vasoactive pattern, i.e. preferential relaxation of the afferent arteriole, was also observed during norepinephrine-induced vasoconstriction [15]. Thus, angiotensin II-induced constriction of the afferent arteriole is dose-dependently reversed not only by dihydropyridine calcium antagonists (i.e. nifedipine, nicardipine, and amlodipine) but also by a benzothiazepine-class antagonist (i.e. diltiazem), whereas the efferent arteriole is refractory to the vasodilator effects of these antagonists. 

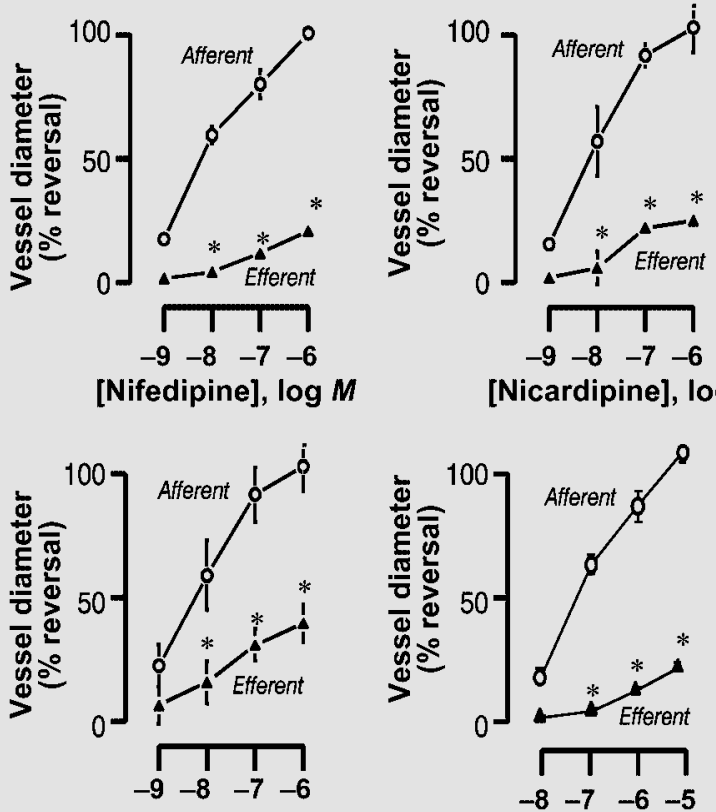

[Amlodipine], $\log M$

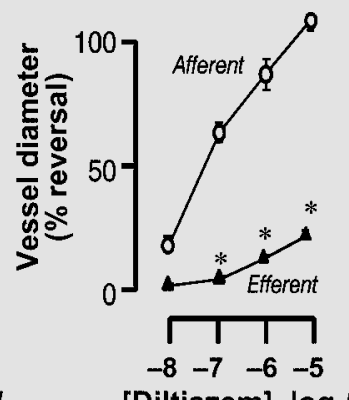

[Diltiazem], $\log M$

Fig. 1. Effects of various calcium antagonists on angiotensin IIinduced constriction of renal microvessels. Both dihydropyridine(nifedipine, nicardipine, and amlodipine) and non-dihydropyridinetype calcium antagonists (diltiazem) reversed the afferent arteriolar constriction. In contrast, efferent arteriolar constriction was relatively refractory to these calcium antagonists. ${ }^{*} \mathrm{p}<0.05$ vs. afferent arterioles. From Hayashi et al. [15].

\section{Segmental Heterogeneity in Localization of Calcium} Channels

The selective action of the conventional types of calcium antagonists could be explained by the heterogeneity in the distribution of voltage-dependent calcium channels within the renal microvasculature. It has been demonstrated that voltage-dependent calcium channels functionally prevail at the afferent arteriole [2, 4, 51-54]. High $\mathrm{K}$-induced membrane depolarization selectively constricts the afferent arteriole, whereas the efferent arteriole is relatively insensitive to the depolarization $[51,53]$. Furthermore, a calcium channel agonist (e.g. Bay K-8644), which directly activates voltage-dependent calcium channels, causes preferential afferent arteriolar constriction [54].

Carmines et al. [53] conducted an elegant study by directly assessing the intracellular calcium concentration $\left(\left[\mathrm{Ca}^{2+}\right]_{\mathrm{i}}\right)$ of isolated rabbit glomeruli with attached afferent and efferent arterioles. They demonstrated that high

K-induced depolarization elevated the $\left[\mathrm{Ca}^{2+}\right]_{\mathrm{i}}$ of the afferent arteriole from $150 \pm 11$ to $196 \pm 12 \mathrm{nmol} / \mathrm{l}$, whereas $\left[\mathrm{Ca}^{2+}\right]_{\mathrm{i}}$ of the efferent arteriole was reduced from $188 \pm$ 17 to $148 \pm 13 \mathrm{nmol} / \mathrm{l}$, probably because of a decrease in electrochemical gradient driving force of $\mathrm{Ca}^{2+}$ leak into cells. They also demonstrated that the inhibition of voltage-dependent calcium channels by nifedipine completely prevented the high $\mathrm{K}$-induced rise in $\left[\mathrm{Ca}^{2+}\right]_{\mathrm{i}}$.

Very recently, Hansen et al. [55] have demonstrated a selective expression of the mRNA encoding $\mathrm{Ca}_{\mathrm{v}} 1.2 \mathrm{~L}$-type calcium channel subunits in rabbit afferent arterioles. In contrast, no subunit is found in cortical efferent arterioles, although these channel subunits are expressed at juxtamedullary efferent arterioles.

In summary, from observations obtained under direct and indirect activation of voltage-dependent calcium channels, it is reasonable to conclude that voltage-dependent calcium channels predominate at the afferent arteriole. In contrast, these channels are sparse or functionally silent at the efferent arteriole. Such functional heterogeneity of the renal microvasculature greatly influences the actions of calcium antagonists on renal hemodynamics.

\section{Direct Evidence for Efferent Arteriolar Dilation by \\ Novel Calcium Antagonists}

In contrast to the predominant action on the afferent arterioles of conventional types of calcium antagonists, the observation described above suggests a substantial role of efferent arteriolar dilation in mediating reduced filtration fraction by manidipine, nilvadipine, and efonidipine (table 1). Furthermore, the assessment of renal arteriolar resistance with the use of renal function curves indicates an efferent arteriolar dilation by benidipine in human nondiabetic nephropathy [56]. Very recently, a growing body of direct evidence for efferent arteriolar action of certain types of calcium antagonists has been accumulated.

Tojo et al. [19] have reported that manidipine elicits both afferent and efferent arteriolar dilation in the in vivo hydronephrotic kidney models, although the magnitude of the efferent arteriolar dilation is still less than that of the afferent arteriolar dilation. Using the microdissected renal arterioles, Arima et al. [21] also reported that manidipine caused efferent as well as afferent arteriolar dilation. Furthermore, Zhou et al. [57] showed decreases in both afferent and efferent arteriolar resistance by cilnidipine in nitro- $L$-arginine methylester-treated SHR. Finally, Takabatake et al. [36] reported that in the rat micropuncture study, efonidipine reduces both pre- and postglomerular capillary resistance. 
Although these observations suggest divergent action of calcium antagonists on the efferent arteriole, there remains the possibility that different experimental conditions may affect the renal microvascular responsiveness to these agents. Nevertheless, we have demonstrated that several calcium antagonists including manidipine, nilvadipine, benidipine, and efonidipine, cause substantial dilation of efferent arterioles in the isolated perfused rat hydronephrotic kidney (fig. 2) [15, 16-18]. In contrast, in the same preparation, both dihydropyridine-class (nifedipine, nicardipine, and amlodipine) and non-dihydropyridine-class calcium antagonists (diltiazem) cause predominant afferent arteriolar dilation (fig. 1) [15]. Thus, our observations militate against the possibility that differing renal arteriolar action of calcium antagonists depends on the experimental settings used, and would indicate the heterogeneity in the action of calcium antagonists on the efferent arteriole. Since these traditional calcium antagonists act on L-type voltage-dependent calcium channels and these channels prevail predominantly at the afferent arteriole [51-55], the effects on the efferent arteriole by these calcium antagonists are most likely attributed to additional actions of these antagonists, but not due to the class effects of these agents.

There exists some possibility that the above observations obtained from the isolated perfused hydronephrotic kidney model might be distorted because of the nature of its experimental setting. To circumvent this possibility, we have further extended our premise, with the use of intravital pencil-lens CCD camera technique [50, 58-62] (fig. 3). This experimental technique is unique because in vivo, in situ, and relatively intact renal microcirculation is accessible by simply introducing the pencil-lens probe into the renal cortex, without disrupting the renal microvascular responsiveness to tubuloglomerular feedback mechanism or angiotensin II [50]. Using this experimental technique, we confirmed heterogeneity in the action of calcium antagonists on the renal microcirculation. Thus, filtration fraction was elevated with nifedipine, tended to decrease with efonidipine, and reduced with mibefradil (fig. 4) [63]. Furthermore, these observations precisely coincide with the renal arteriolar responsiveness to these antagonists in this experimental setting (fig. 4) [61], and again strongly support our formulation that the effects of calcium antagonists vary depending on the types of the antagonists used.

In concert, both in vivo and in vitro studies indicate the heterogeneity in the renal microvascular action of the calcium antagonist. Based on the ratio of efferent to afferent arteriolar action, we propose that calcium antagonists
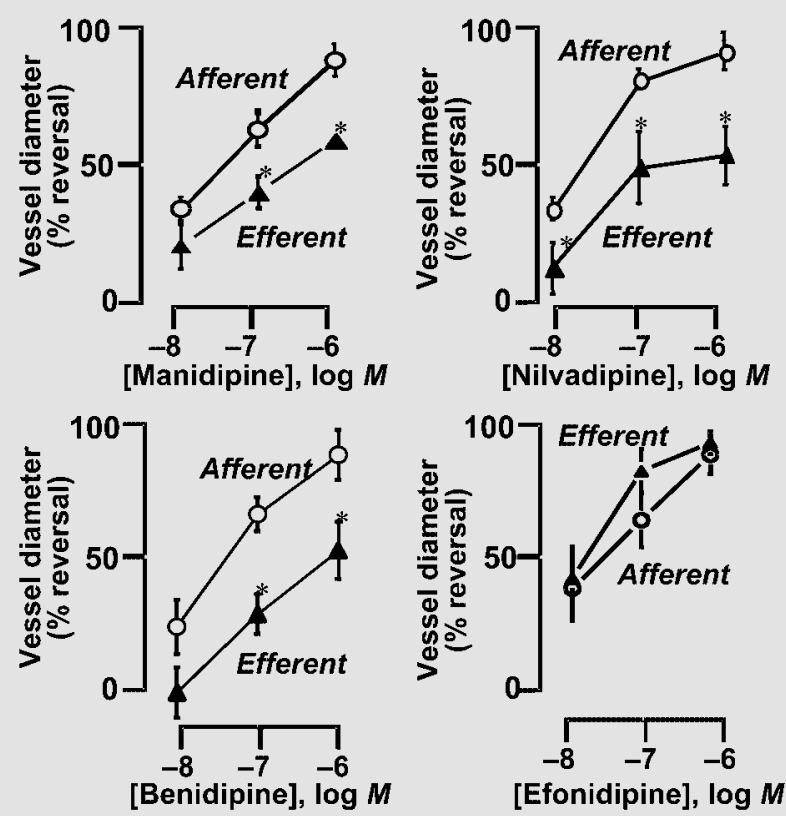

Fig. 2. Effects of novel calcium antagonists on angiotensin IIinduced constriction of renal microvessels. Manidipine, nilvadipine, benidipine, and efonidipine elicited dilation of efferent, as well as afferent, arterioles. The vasodilator action on the efferent arteriole was the most marked with efonidipine. $* \mathrm{p}<0.05 \mathrm{vs}$. afferent arterioles. From Hayashi et al. [64].

are categorized into three groups: (1) group I, acting preferentially on the afferent arteriole (nifedipine, nicardipine, amlodipine, diltiazem, and pranidipine); (2) group II, dilating both afferent and efferent arterioles, but the effect on the efferent arteriole is less than that on the afferent arteriole (manidipine, benidipine, and nilvadipine); (3) group III, which dilates efferent as well as afferent arterioles in almost the same magnitude (efonidipine) (fig. 5) [64]. This classification would offer helpful information in assessing the glomerular capillary pressure.

Of interest, lercanidipine, recently marketed in Europe, is potent in inhibiting afferent but not efferent arterioles. In contrast to the acute renal microvascular action of lercanidipine, Sabbatini et al. [65] demonstrate the histological dilatation of efferent as well as afferent arteriolar lumen by 12 -week treatment with lercanidipine in spontaneously hypertensive rats. Thus, the renal microvascular effect of the long-term treatment with calcium antagonists may alter the structural changes in renal microvascular beds.

Am J Nephrol 2003;23:229-244 
Fig. 3. Direct in vivo visualization of renal microcirculation with the use of intravital pencil-type CCD videomicroscopy. From Matsuda et al. [60].

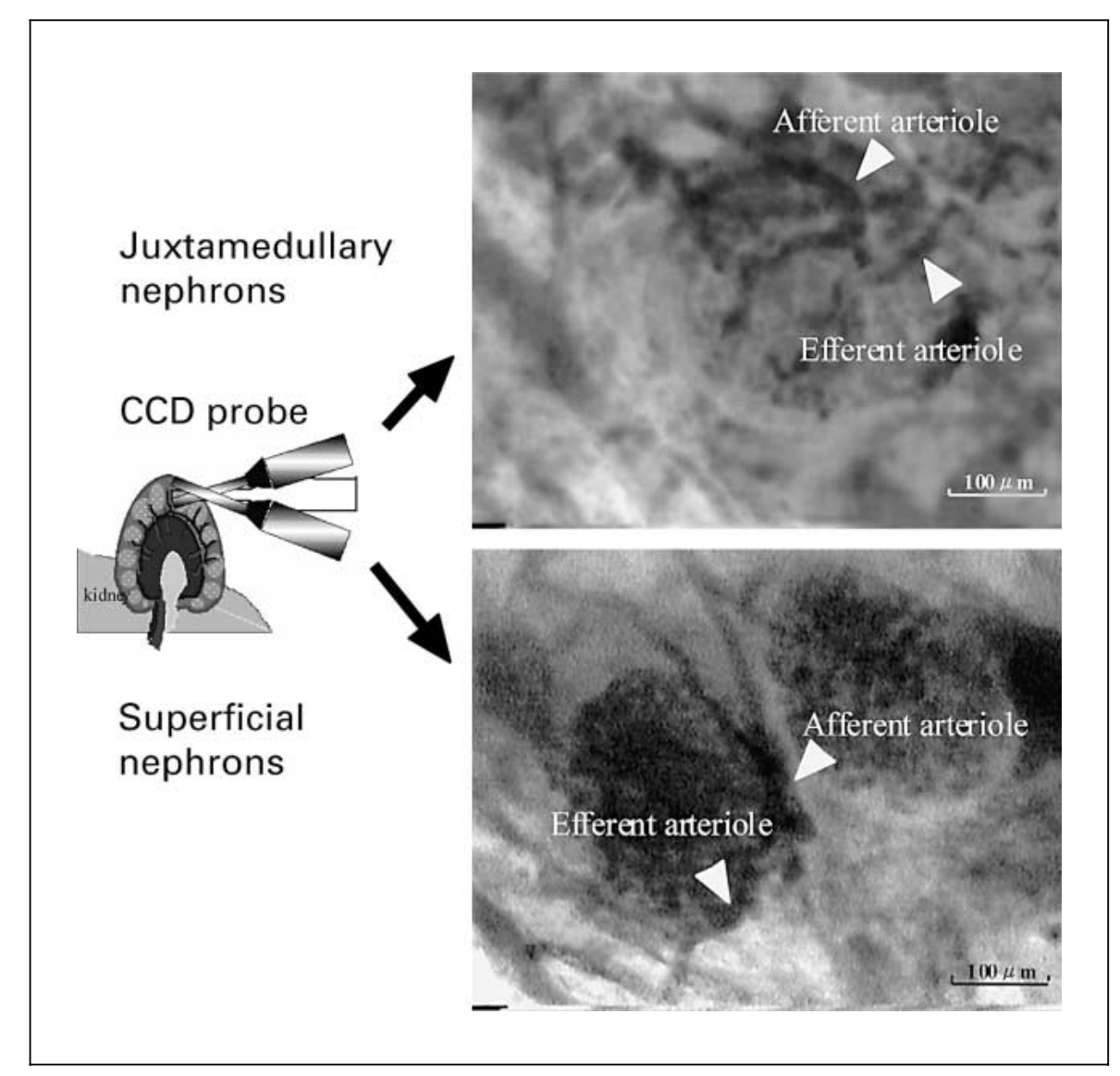

\section{Mechanism for Efferent Arteriolar Vasodilation}

As described, several calcium antagonists elicit efferent as well as afferent arteriolar dilation [15-21]. The mechanisms for the efferent arteriolar vasodilation, however, remain undetermined. We therefore examined the role of nitric oxide and vasodilatory prostaglandins in mediating the efonidipine-induced efferent arteriolar dilation. Neither nitro- $L$-arginine methylester nor indomethacin, however, had any effect on efonidipine-induced efferent arteriolar vasodilation [66]. Similarly, our laboratory [15] and Arima et al. [21] have indicated that manidipine causes efferent arteriolar dilation, with nearly the same magnitude as that induced by nilvadipine. Of interest, Arima et al. [21] suggested that a part of manidipine-induced efferent arteriolar dilation was mediated by glomerulus-derived vasodilators other than nitric oxide.

A recent pharmacological study has witnessed that efonidipine possesses the blocking activity on T-type, as well as L-type, voltage-dependent calcium channels [67]. Although T-type calcium channels are closely associated with pacemaking potentials [68], the role of these calcium channel subtypes in the vasculature remains poorly understood. In several microvasculature including mesenteric [69] and cremaster arterioles [70], T-type calcium channels are distributed substantially, and the blockade of these channels by a selective T-type calcium channel blocker, mibefradil, inhibits the vasoconstriction of these arterioles. In the renal microvasculature, Hansen et al. [55] have demonstrated that T-type calcium channels prevail at juxtamedullary efferent arterioles, as well as afferent arterioles of superficial and juxtamedullary nephrons. Furthermore, in a preliminary report, Ono's group has recently shown the presence of a $\mathrm{Ca}_{\mathrm{v}} 3.1$ subunit (an $\alpha_{1}$ subunit of T-type calcium channels) at superficial efferent as well as afferent arterioles, with the use of in situ hybridization (a personal communication). In accordance with the distribution of T-type calcium channels, Nakamura et al. [71] found that mibefradil decreased both afferent and efferent arteriolar resistance in SHR kidneys, using the micropuncture technique. Recently, Ozawa et al. [18] have directly visualized an efferent arteriolar dilation by some calcium antagonists which possess the blocking 

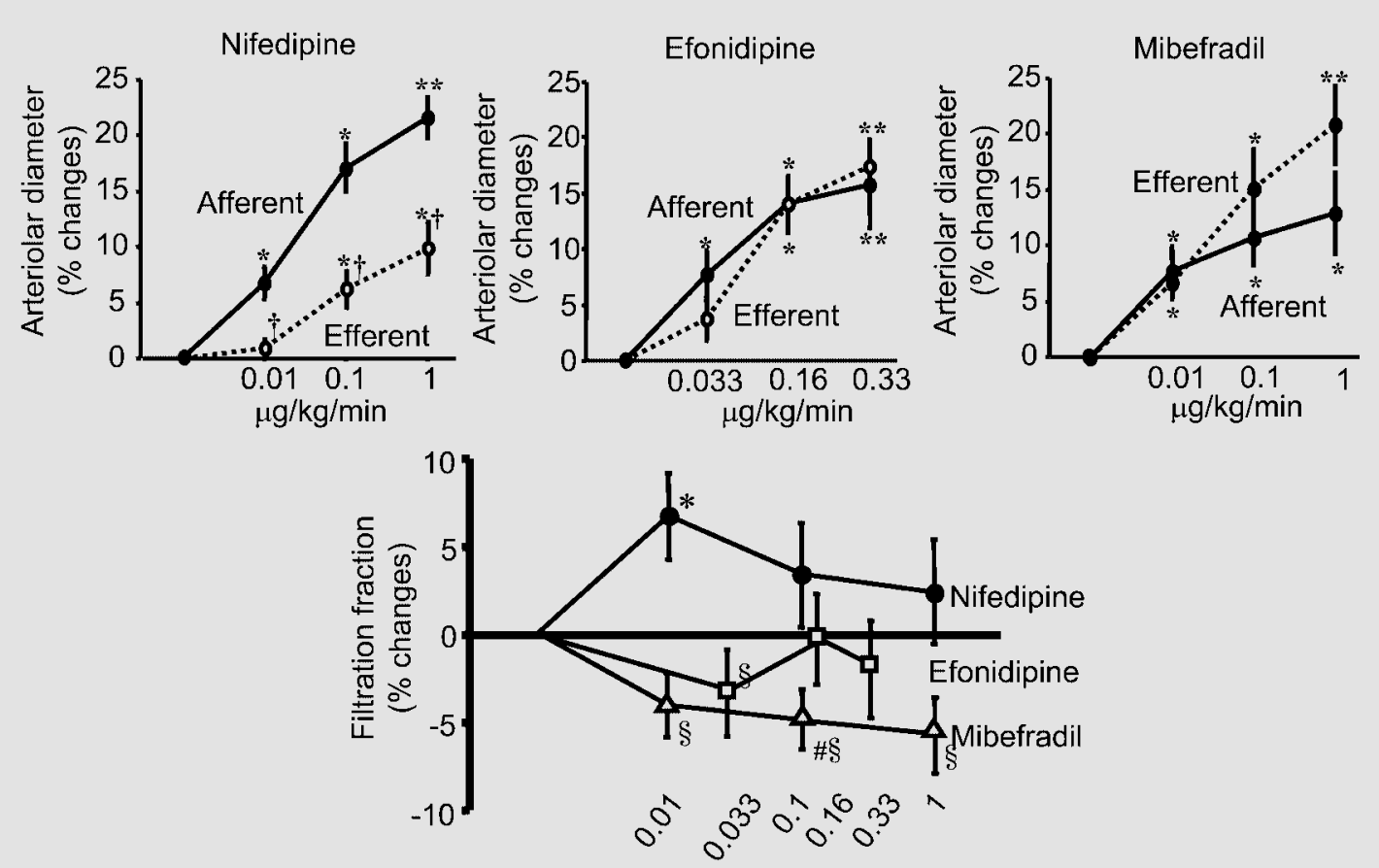

[Calcium antagonists, $\mu \mathrm{g} / \mathrm{kg} / \mathrm{min}$ ]

Fig. 4. Effects of various calcium antagonists on in vivo renal microvessels and renal hemodynamics. Predominant afferent arteriolar action of nifedipine and potent dilation by efonidipine and mibefradil closely parallel the changes in filtration fraction. ${ }^{*} \mathrm{p}<0.05$ vs. baseline; ${ }^{\#} \mathrm{p}=0.05$ vs. baseline; ${ }^{\dagger} \mathrm{p}<0.05$ vs. afferent arterioles; ${ }^{\S} \mathrm{p}<0.05$ vs. nifedipine. Adopted with modification from Honda et al. [63].

Fig. 5. Divergent vasodilator action of calcium antagonists on efferent arterioles. Based on the relative activity on efferent vs. afferent arterioles, calcium antagonists are classified into 3 groups. The first group of calcium antagonists (e.g. nifedipine) elicits predominant vasodilation of afferent arterioles, with modest action on efferent arterioles. The second group (e.g. nilvadipine) produces both afferent and efferent arteriolar vasodilation, although the efferent arteriolar dilation is less than that on the afferent arteriole. The third group of calcium antagonists (e.g. efonidipine) potently relaxes both afferent and efferent arterioles, with nearly the same activity on these vessels. $* \mathrm{p}<0.05$ vs. baseline. ? = Not examined. From Hayashi et al. [64].

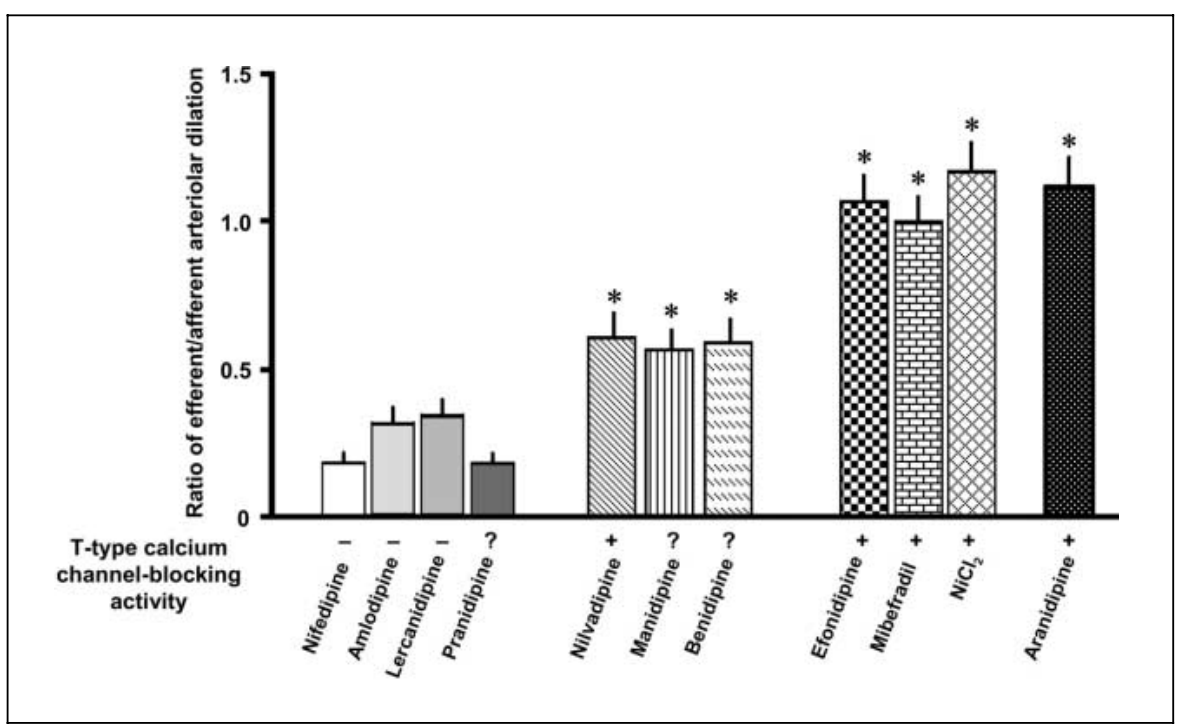

Am J Nephrol 2003;23:229-244 
Fig. 6. Effects of T-type Ca channel blockade on angiotensin II-induced constriction of renal arterioles. Both mibefradil and $\mathrm{NiCl}_{2}$ elicited dose-dependent dilation of renal microvessels, similar in magnitude in afferent (circles) and efferent arterioles (squares; ${ }^{*} \mathrm{p}<0.05$ vs. angiotensin $\mathrm{II} ;{ }^{\dagger} \mathrm{p}<$ 0.05 ; upper). In contrast, nifedipine caused modest dilation of efferent arterioles, whereas dilating afferent arterioles prominently. The subsequent addition of mibefradil elicited further dilation of efferent arterioles $\left({ }^{*} \mathrm{p}<0.05\right.$ vs. angiotensin $\mathrm{II} ;{ }^{\dagger} \mathrm{p}<0.05$ vs. nifedipine; lower). From Ozawa et al. [18].
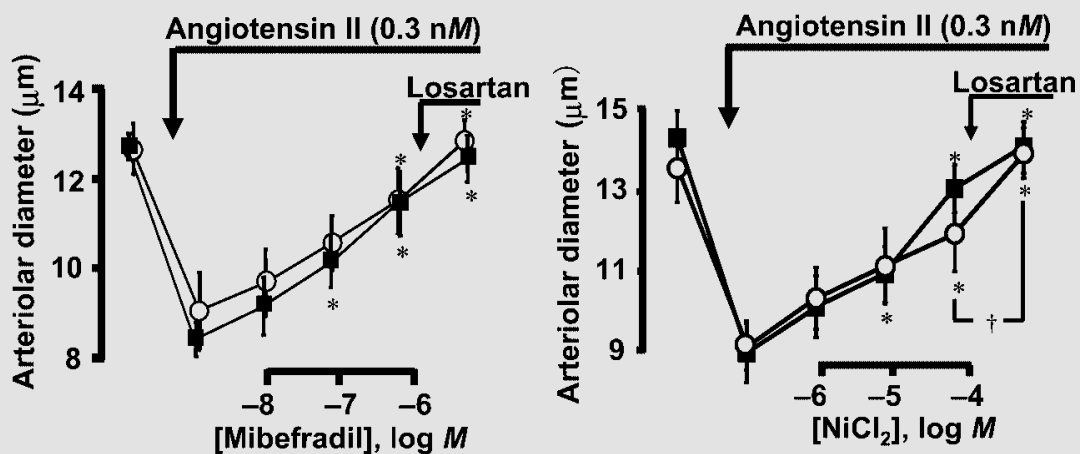

[Mibefradil], $\log M$

Angiotensin II (0.3 $\mathrm{nM})$

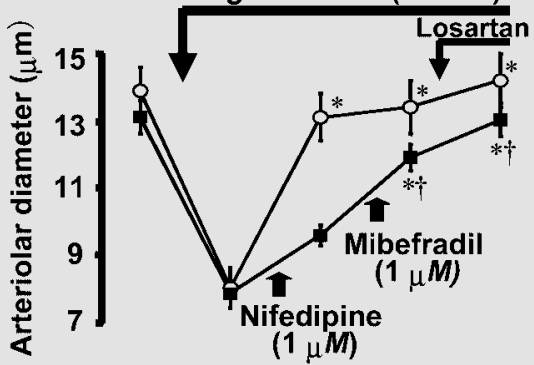

activity on T-type calcium channels. Both mibefradil and nickel chloride potently reverse the angiotensin II-induced constriction of the efferent arteriole in the isolated perfused rat hydronephrotic kidney model (fig. 6). Furthermore, the intravital pencil-type CCD camera technique reveals that efonidipine and mibefradil provoke efferent as well as afferent arteriolar dilation in dog kidneys [61] (fig. 4). Finally, nilvadipine and aranidipine, both of which are reported to possess T-type as well as L-type calcium channel-blocking activity [72, 73], share the same properties with efonidipine with regard to the efferent arteriolar action. These novel findings therefore suggest a critical role of T-type calcium channels in mediating the efferent arteriolar tone.

The mechanism whereby T-type calcium channel activity modifies the intracellular vasoconstrictor signaling pathway and thus dilates efferent arterioles remains undetermined. It is established that angiotensin II-induced vasoconstriction is mediated by two main intracellular signaling pathways, protein kinase $\mathrm{C}$ (PKC) and inositol1,4,5-trisphosphate (IP3)-induced intracellular calcium release $[74,75]$. In the efferent arteriole, we have recently demonstrated that during the angiotensin II stimulation, both PKC- and IP3-associated vasoconstrictor mechanisms are activated in an additive manner [74, 75]. In this regard, mibefradil is reported to inhibit the PKC-mediated signaling pathway and prevent the vascular smooth muscle contraction in the vascular smooth muscle cell [76]. Furthermore, Sipido et al. [77] reported that T-type channel activation facilitated $\mathrm{Ca}^{2+}$ release from sarcoplasmic reticulum in cardiac myocytes. We therefore examined the interaction between these intracellular mechanisms and mibefradil-induced vasodilation [78]. Thus, the PKC stimulation is relatively refractory to the vasodilator action of mibefradil (fig. 7). In the presence of thapsigargin, whereby the administration of ANG II should stimulate the PKC-mediated vasoconstrictor pathway dominantly $[74,75]$, mibefradil had only modest effect on the efferent arteriolar constriction. Indeed, mibefradil was less potent in reversing the phorbol myristate acetate (PMA)-induced constriction of the efferent arteriole, whereas LOE908, a nonselective cation channel blocker [79], nearly completely inhibited this response. In contrast, in the presence of staurosporine, the ANG IIinduced vasoconstriction of efferent arterioles is highly sensitive to the vasodilator action of mibefradil (fig. 7). Since staurosporine prevents the PKC-mediated constrictor mechanism, the major remaining vasoconstrictor mechanism of ANG II should be an IP3-mediated Ca release pathway $[74,75]$. In concert, these observations 
Fig. 7. Effects of T-type Ca channel blockade on angiotensin II-induced constriction of renal arterioles. Mibefradil elicited a dosedependent vasodilation of renal microvessels, similar in magnitude in afferent and efferent arterioles (top). In the presence of staurosporine, both afferent and efferent arterioles exhibited identical degrees of vasodilation, although the vasoconstrictor response of the afferent arteriole was less than that of the efferent arteriole (bottom left). The pretreatment with thapsigargin prevented the angiotensin II-induced constriction of the afferent arteriole, and diminished the efferent arteriolar response to angiotensin II. The subsequent addition of mibefradil elicited only modest dilation of the efferent arteriole (bottom right). ANG II = Angiotensin II; PLC $=$ phospholipase C IP3 = inositol 1,4,5trisphosphate; $\mathrm{PKC}=$ protein kinase $\mathrm{C} .{ }^{*} \mathrm{p}<$ 0.05 vs. angiotensin II; $* * p<0.01$ vs. angiotensin II. From Hayashi et al. [78].

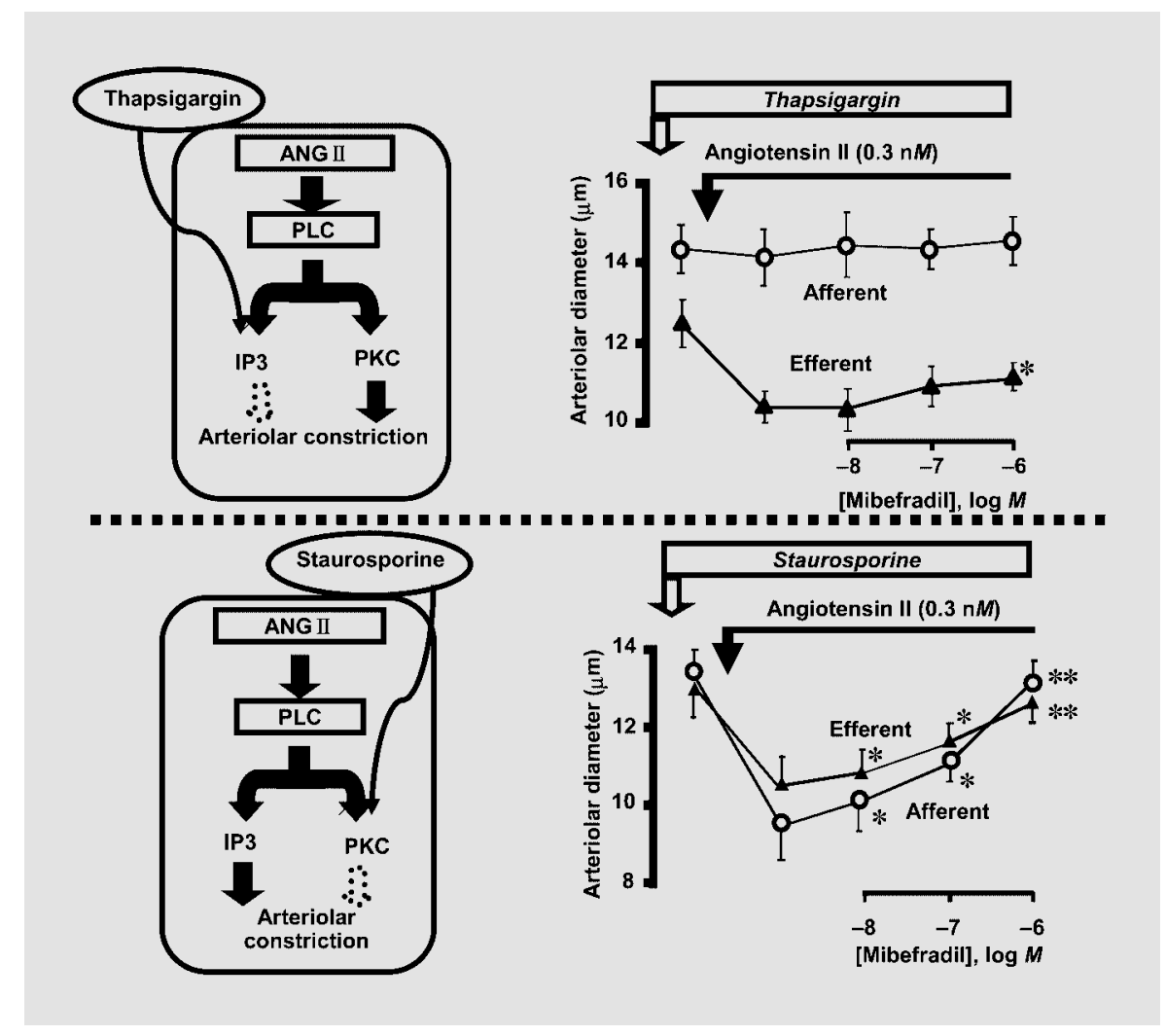

are consistent with the view that that the IP3-mediated pathway constitutes an important target for the action of mibefradil during the ANG II-induced arteriolar constriction.

Although the link between T-type calcium channels and sarcoplasmic $\mathrm{Ca}$ release remains undetermined, recent investigations suggest an intimate interaction between the plasma membrane and the endoplasmic reticulum, which is proposed as a conformational coupling model [80]. Thus, T-type Ca channels within the plasma membrane may communicate with the sarcoplasmic $\mathrm{Ca}$ regulation. Indeed, T-type channel activation is reported to facilitate $\mathrm{Ca}^{2+}$ release from sarcoplasmic reticulum in cardiac myocytes [77]. Further studies are requires to determine how T-type $\mathrm{Ca}$ channels interact with this constrictor mechanism.

Additional mechanisms for the efferent arteriolar dilation by recently-developed calcium antagonists merit comment. It has been reported that T-type calcium channel activation stimulates renin release. Wagner et al. [81] have demonstrated that mibefradil suppresses renin release. This observation raises the possibility that T-type calcium channel blockade inhibits the angiotensin II pro- duction, and therefore would be anticipated to contribute in part to the efferent arteriolar vasodilation (table 2). Furthermore, cilnidipine, a novel calcium antagonist possessing both L- and N-type calcium channel blocking activity, has been developed, and is available in a clinical setting in Japan [82]. This antagonist is unique because of this pharmacological characteristics, i.e. the inhibitory action on neural stimulation-mediated norepinephrine secretion [83]. Using this antagonist, Zhou et al. [57] have demonstrated decreases in both afferent and efferent arteriolar resistance in nitro- $L$-arginine methylester-treated SHR. Since the sympathetic nerve activity, which causes constriction of both afferent and efferent arterioles, is reported to be enhanced in this model [84], the inhibition of N-type Ca channels by cilnidipine would dilate both arterioles in this setting. Similarly, amlodipine is demonstrated to possess the inhibitory action on both L-type and $\mathrm{N}$-type Ca channels [85]. Although amlodipine predominantly dilates the afferent arteriole in the isolated perfused hydronephrotic kidney [15], this antagonist is also reported to cause a substantial dilation of efferent, as well as afferent, arterioles in the in vivo hydronephrotic kidney [86]. Although these discrepant observations may be 
Table 2. Possible mechanisms for renal protective action of calcium antagonists

\begin{tabular}{|c|c|c|c|}
\hline & $\mathrm{Ca}$ antagonists & & ACE inhibitors \\
\hline Ca channel inhibition & $\begin{array}{l}\text { L-type Ca channels } \\
\text { nifedipine } \\
\text { amlodipine } \\
\text { nicardipine }\end{array}$ & $\begin{array}{l}\text { L+T-type Ca channels } \\
\text { mibefradil } \\
\text { efonidipine } \\
\text { nilvadipine }\end{array}$ & \\
\hline Renin-angiotensin inhibition & - & + & + \\
\hline Renal vasodilator action & $\mathrm{AFF} \gg \mathrm{EFF}$ & $\mathrm{AFF}>=\mathrm{EFF}$ & $\mathrm{AFF}<=\mathrm{EFF}$ \\
\hline Systemic depressor action & $\downarrow \sim \downarrow \downarrow$ & $\downarrow \sim \downarrow \downarrow$ & $\downarrow \sim \downarrow \downarrow$ \\
\hline Glomerular capillary pressure & $\begin{array}{l}\text { increase or decrease (depending } \\
\text { on the magnitude of systemic } \\
\text { hypotensive action) }\end{array}$ & decrease & decrease \\
\hline Renal protective action & - or + & + & + \\
\hline
\end{tabular}

attributed to the difference in the experimental settings, further investigations are required to clarify this issue.

\section{Role of Calcium Antagonists in the Progression of \\ Renal Injury in Animals}

The glomerular hemodynamic effects of traditional calcium antagonists suggest that these antagonists fail to correct glomerular hypertension in certain experimental conditions [87-89]. The long-term effect of the calcium antagonist on injured kidney is conflicting. Since the net effect of calcium antagonists on glomerular hemodynamics is determined by the balance between the reduction in afferent arteriolar resistance and the fall in systemic blood pressure, and the changes in these two factors may vary depending on the experimental settings, magnitude of depressor activity, or types of calcium antagonists used. Alternatively, although calcium antagonists inhibit the pressure-induced (i.e. myogenic) tone [90, 91], the differing degrees of impairment of renal autoregulation by calcium antagonists may affect the development of glomerulosclerosis $[13,14,92]$. Thus, verapamil is reported to reduce proteinuria and protect against renal injury in remnant kidney models [93, 94]. Furthermore, Dworkin et al. $[89,95,96]$ demonstrated that nifedipine reduced both urinary protein excretion and glomerular injury in subtotally nephrectomized rats, uninephrectomized SHR and DOCA-salt hypertensive rats, despite the persistent glomerular hypertension. In contrast, there have been several reports suggesting deleterious effects of dihydropyri- dine-class calcium antagonists in renal diseases [11-14, 89, 97, 98]. Wenzel et al. [97] demonstrated that nitrendipine did actually increase proteinuria and glomerulosclerosis in two kidney one clip model of hypertension. Furthermore, Dworkin et al. [95] also found that amlodipine did not exhibit renoprotective action in DOCA-salt hypertensive rats. Finally, felodipine impaired renal autoregulation more markedly than verapamil or diltiazem, which tended to parallel the degree of glomerulosclerosis $[14,92]$.

In contrast, the novel calcium antagonists, acting on both afferent and efferent arterioles, may correct glomerular hypertension, and could therefore exert salutary actions on the progression of renal injury. Indeed, Takakura et al. [37] indicated that nilvadipine profoundly improved renal histological changes as well as renal function, despite only a modest reduction in blood pressure in strokeprone SHR. Furthermore, Shudo et al. [99-101] reported that efonidipine acutely decreased proteinuria in spontaneously hypertensive rats, whereas systemic blood pressure was only partially reduced. Additionally, Fujimaki et al. [102] found that manidipine exerted salutary action on renal structure in uninephrectomized spontaneously hypertensive rats. Finally, it has recently been reported that mibefradil potently prevents the development of renal injury in SHR [71] and DOCA hypertensive rats [103]. In contrast, in the remnant kidney model, mibefradil is demonstrated to impair renal autoregulation and accelerate the progression of glomerulosclerosis [104]. The inconsis- 
Fig. 8. Effects of 12-week treatment with various calcium antagonists on systolic blood pressure and urinary protein excretion in subtotally nephrectomized spontaneously hypertensive rats. ${ }^{*} \mathrm{p}<0.05$ vs. control.

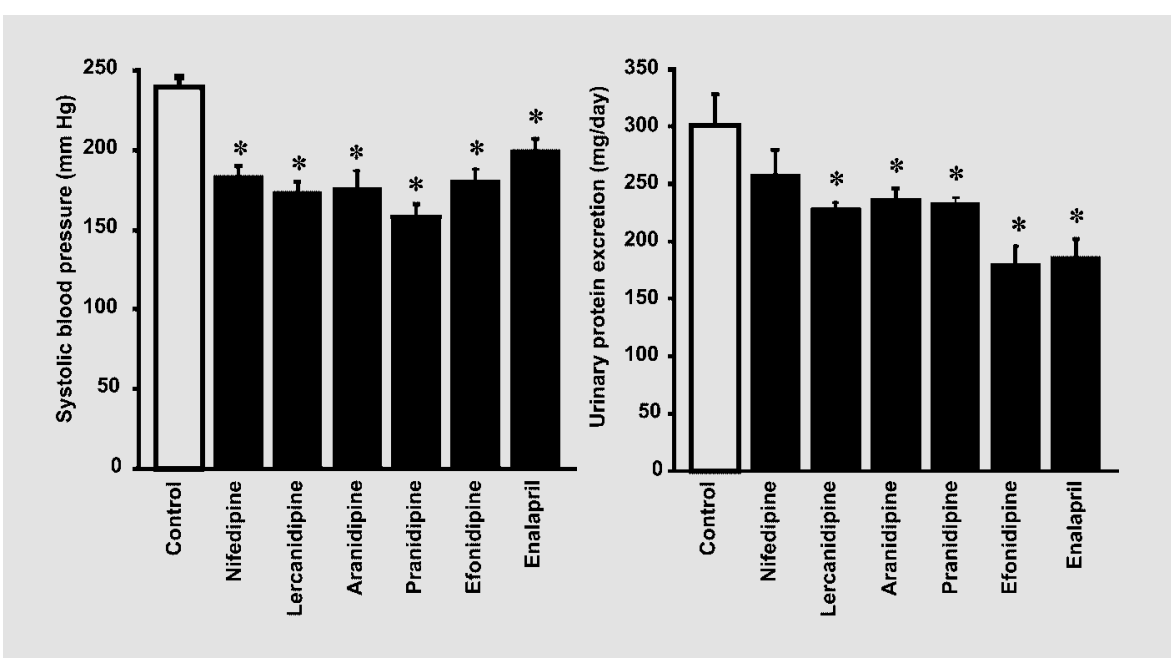

tent efficacy of mibefradil might be attributable to different roles of T-type calcium channels in the efferent arteriole of these experimental animals.

Our previous studies demonstrated that 8-week-treatment with calcium antagonists, including nicardipine [105], amlodipine [106], efonidipine [107], pranidipine [108], lercanidipine [64] and aranidipine [20] prevent the progression of renal injury in subtotally nephrectomized SHR. Thus, these calcium antagonists exert marked reductions in systemic blood pressure (fig. 8). Furthermore, the histopathological changes and serum creatinine levels were also ameliorated. Despite the amelioration by these agents, the effects of these agents on proteinuria differ. Thus, nifedipine tended to decrease urinary protein excretion, and other calcium antagonists, including lercanidipine, pranidipine and efonidipine, significantly reduced proteinuria (fig. 8). Of note, among the calcium antagonists examined, efonidipine most prominently decreased urinary protein excretion; it reduced proteinuria to the same level as enalapril, which causes both afferent and efferent arteriolar dilation. Thus, the renal protective effect of efonidipine may be associated with the glomerular hemodynamic action of this agent, since efonidipine is anticipated to reduce glomerular capillary pressure, as well as enalapril. In concert with acute proteinuria-reducing effect, chronic effects of efonidipine on proteinuria suggest a beneficial effect of this calcium antagonist on glomerular capillary pressure, and this could be mediated by renal hemodynamic effect on the efferent arteriole. Although obviously the beneficial effects of calcium antagonists are not totally ascribed to glomerular hemodynamic action, the proteinuria-reducing effect of efonidi- pine would suggest an important role of glomerular hemodynamic factors, i.e. efferent arteriolar dilation, in blunting the progression of renal disorders. Caveat is in order, however, since preferential afferent arteriolar dilation following subtotal nephrectomy [109] may influence the action of calcium antagonists. Thus, the ability of afferent arteriole-selective calcium antagonists to ameliorate glomerular hypertension may depend largely on whether systemic hypertension is corrected in this experimental setting. In contrast, the efferent arteriole-acting calcium antagonist as well as enalapril would predispose glomerular capillary pressure to decline in addition to hypotensive action. Consequently, the contrasting effects of these antihypertensive agents on proteinuria may be unique in this experimental model.

As stated above, multiple mechanisms appear to contribute to the ability of the calcium antagonist to protect the kidney. Besides glomerular hemodynamic factors, the calcium antagonist has been demonstrated that attenuates mesangial entrapment of macromolecules $[110,111]$, and suggested to countervail the mitogenic effect of plateletderived growth factor and platelet-activating factor [110]. Similarly, calcium antagonists suppress mesangial cell proliferation by inhibiting activator protein-1 (AP-1) [112] as well as the cell cycle transition from the G1 to S phase [113], and modulate gene transcriptions that are involved in proinflammatory changes (interleukin- $1 \beta$ and granulocyte/monocyte colony-stimulating factors) [114]. In this regard, calcium antagonists have been shown to suppress the PMA-induced activation of nuclear factor kappa $\mathrm{B}(\mathrm{NF \kappa B})$ in cultured human mesangial cells, this action is the most prominent with efonidipine [115]. 
Fig. 9. Effects of angiotensin-converting enzyme inhibitors and efonidipine on systemic blood pressure and urinary protein excretion in patients with proteinuria $>1 \mathrm{~g} /$ day. Circles $=$ Angiotensin-converting enzyme inhibitors; triangles $=$ efonidipine. ${ }^{*} \mathrm{p}<0.05$ vs. 0 week. From Hayashi et al. [118].

Fig. 10. Role of systemic blood pressure in the development of proteinuria in patients with proteinuria $>1 \mathrm{~g} /$ day treated with angiotensin-converting enzyme inhibitors and efonidipine. ACE-I = Angiotensin-converting enzyme inhibitors. MAP = Mean arterial pressure. From Hayashi et al. [118].
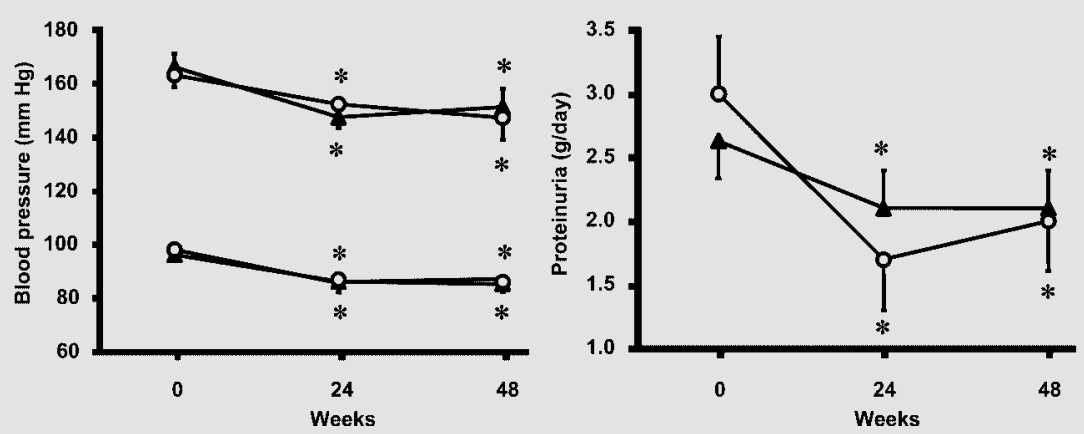

ACE-I

MAP $>100$ mm Hg

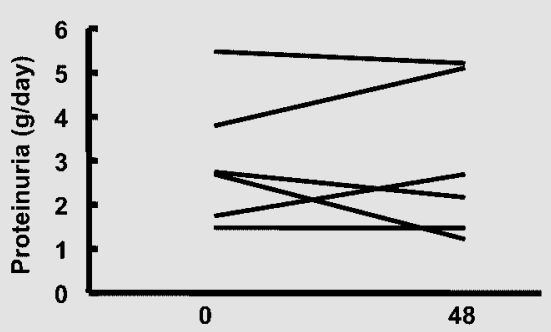

MAP $<100 \mathrm{~mm} \mathrm{Hg}$

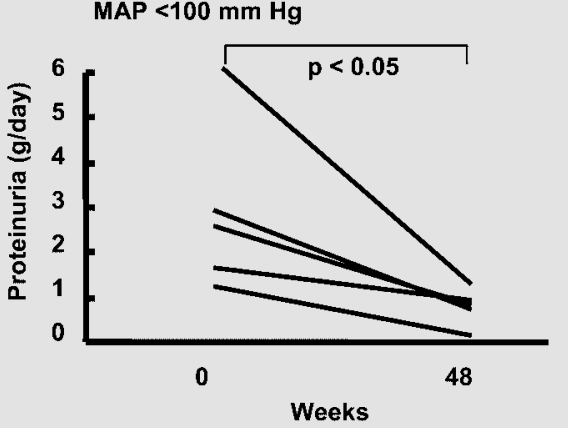

Efonidipine

MAP $>100 \mathrm{~mm} \mathrm{Hg}$
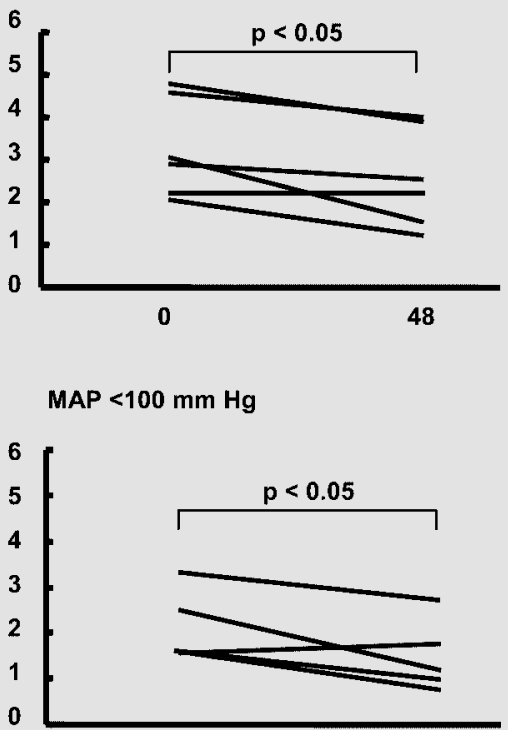

MAP $<100 \mathrm{~mm} \mathrm{Hg}$

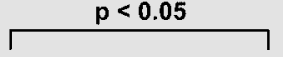

Weeks
Finally, calcium antagonists could act as free radical scavengers $[116,117]$.

\section{Effect of Efonidipine on the Progression of Renal \\ Injury in Human Renal Disease}

Although the formulation that the efferent arteriolar dilation constitutes a determinant of the renal protective action of the antihypertensive agents is well established with the use of ACE inhibitors in both experimental animals and humans, it remains undetermined whether the T-type calcium channel inhibition at the efferent arteriole contributes to the renal protection in human chronic renal disease. We therefore compared the effect of efonidipine on the progression of renal disease with that of ACE inhibitors [118]. Thus, 12 month-treatment with efonidipine in patients with non-diabetic renal disease elicited nearly the same magnitude of the reduction in proteinuria with that of ACE inhibitors (fig. 9). In contrast, efonidipine provoked less adverse effects such as non-productive cough and hyperkalemia. Of note, in patients in which mean systemic blood pressure did not achieve a level below 100 $\mathrm{mm} \mathrm{Hg}$, proteinuria was significantly decreased (fig. 10). This observation suggests a renal protective action of efonidipine independent of the level of systemic blood 
pressure, and may be associated with intrarenal action of this agent, including efferent arteriolar dilation. It should be stated, however, that whereas amlodipine is detrimental in the progression of renal disease in hypertensive nephrosclerosis [119], amlodipine is also demonstrated to confer more substantial renal protective action than diuretics or ACE inhibitors when the systemic blood pressure is reduced to an optimal level [120]. Thus, the ability of the calcium antagonists that possess predominant activity on afferent arterioles may vary depending on the level of blood pressure achieved (table 2).

In conclusion, in both experimental and human renal disease, the calcium antagonists with the dilatory activity on efferent arterioles would confer beneficial action on glomerular capillary pressure. Furthermore, it appears that this action on glomerular microcirculation is anticipated to retard the progression of renal injury.

\section{Conclusion}

Previous investigations demonstrated that calcium antagonists caused preferential dilation of the afferent arteriole. In contrast, recently several calcium antagonists, acting uniquely on the renal microcirculation, have been developed, with the property of vasodilator action on both afferent and efferent arterioles. The present review extends our previous observations, and further allows characterization of the calcium antagonist with respect to the renal microvascular effect. Based on the heterogeneity in the renal microvascular action of the calcium antagonist, we propose a new classification of this agent. This categorization may offer helpful information in assessing the glomerular capillary pressure in the treatment of hypertension.

\section{References}

1 Reams GP, Bauer JH: Acute and chronic effects of calcium antagonists on the essential hypertensive kidney; in Epstein M, Loutzenhiser R (eds): Calcium Antagonists and the Kidney. Philadelphia, Hanley \& Belfus, 1990, pp 247-256.

2 Carmines PK, Navar LG: Disparate effects of $\mathrm{Ca}$ channel blockers on afferent and efferent arteriolar responses to ANG II. Am J Physiol 1989;256:F1015-F1020.

3 Loutzenhiser R, Epstein M: Renal hemodynamic effects of calcium antagonists; in Epstein M, Loutzenhiser R (eds): Calcium Antagonists and the Kidney. Philadelphia, Hanley \& Belfus, 1990, pp 33-74.

4 Fleming JT, Parekh N, Steinhausen M: Calcium antagonists preferentially dilate preglomerular vessels of hydronephrotic kidney. Am J Physiol 1987;253:F1157-F1163.

5 Kon V, Fogo A, Ichikawa I: Bradykinin causes selective efferent arteriolar dilation during angiotensin I converting enzyme inhibition. Kidney Int 1993;44:545-550.

6 Ichikawa I: Will angiotensin II receptor antagonists be renoprotective in humans? Kidney Int 1996;50:684-692.

7 Dworkin LD: Effects of calcium channel blockers on glomerular injury on experimental glomerular injury. J Am Soc Nephrol 1990;1:S21S27.

8 Kanno Y, Suzuki H, Okada H, Saruta T: Renal protective effects of amlodipine on partially nephrectomized spontaneously hypertensive rats fed a high-salt diet. J Cardiovasc Pharmacol 1994;23:480-484.
9 Nagahama T, Hayashi K, Fujiwara K, Ozawa Y, Saruta T: Characterization of the renal action of pranidipine in the rat. ArzneimittelForsch 2000;50:248-253.

10 Anderson S: Renal hemodynamic effects of calcium antagonists in rats with reduced renal mass. Hypertension 1991;17:288-295.

11 Bidani AK, Schwartz MM, Lewis EJ: Renal autoregulation and vulnerability to hypertensive injury in remnant kidney. Am J Physiol 1987;252:F1003-F1010.

12 Griffin KA, Picken M, Bidani AK: Method of renal mass reduction is a critical determinant of subsequent hypertension and glomerular injury. J Am Soc Nephrol 1994;4:2023-2031.

13 Griffin KA, Picken MM, Bidani AK: Deleterious effects of calcium channel blockers on pressures transmission and glomerular injury in rat remnant kidneys. J Clin Invest 1995;96:793800.

14 Griffin KA, Picken MM, Bakris GL, Bidani AK: Class differences in the effects of calcium channel blockers in the rat remnant kidney model. Kidney Int 1999;55:1849-1860.

15 Hayashi K, Nagahama T, Oka K, Epstein M, Saruta T: Disparate effects of calcium antagonists on renal microcirculation. Hypertens Res 1996;19:31-36.

16 Saruta T, Kanno Y, Hayashi K, Konishi K: Antihypertensive agents and renal protection: Calcium channel blockers. Kidney Int 1996; 55(suppl 49):S52-S56.

17 Ozawa Y, Hayashi K, Nagahama T, Fujiwara K, Wakino S, Saruta T: Renal afferent and efferent arteriolar dilation by nilvadipine: Studies in the isolated perfused hydronephrotic kidney. J Cardiovasc Pharmacol 1999;33:243247.
18 Ozawa Y, Hayashi K, Nagahama T, Fujiwara K, Saruta T: Effect of T-type selective calcium antagonist on renal microcirculation: Studies in the isolated perfused hydronephrotic kidney. Hypertension 2001;38:343-347.

19 Tojo A, Kimura K, Matsuoka H, Sugimoto T: Effects of manidipine hydrochloride on the renal microcirculation in spontaneously hypertensive rats. J Cardiovasc Pharmacol 1992;20: 895-899.

20 Nakamura A, Hayashi K, Fujiwara K, Ozawa Y, Saruta T: Distinct action of aranidipine an its metabolite on renal microvessels - with special reference to renal protection. J Cardiovasc Pharmacol 2000;35:942-948.

21 Arima S, Ito S, Omata K, Tsunoda K, Yaoita $\mathrm{H}$, Abe K: Diverse effects of calcium antagonists on glomerular hemodynamics. Kidney Int 1996;55(suppl):S132-S134.

22 Heller J, Horacek V: The effect of two different calcium antagonists on the glomerular haemodynamics in dogs. Eur J Physiol 1990;415:751755.

23 Bell AJ, Lindner A: Effects of verapamil and nifedipine on renal function and hemodynamics in the dog. Renal Physiol 1984;7:329-343.

24 Dietz JR, Davis JO, Freeman RH, Villarreal D, Echtenkamp SF: Effects of intrarenal infusion of calcium entry blockers in anesthetized dogs. Hypertension 1983;5:482-488.

25 Yokoyama S, Kaburagi T: Clinical effects of intravenous nifedipine on renal function. $\mathrm{J}$ Cardiovasc Pharmacol 1983;5:67-71. 
26 Abe Y, Komori T, Miura K, Takada T, Imanishi M, Okahara T, Yamamoto K: Effects of the calcium antagonist nicardipine on renal function and renin release in dogs. $\mathbf{J}$ Cardiovasc Pharmacol 1983;5:254-259.

27 Smith SA, Rafiqi EI, Gardener EG, Young MA, Little WA: Renal effects of nicardipine in essential hypertension: Differences between acute and chronic therapy. J Hypertens 1987;5: 693-697.

28 Wallia R, Greenberg A, Puschett JB: Renal hemodynamic and tubular transport effects of nitrendipine. J Lab Clin Med 1985;105:498503.

29 Loutzenhiser R, Epstein M, Horton C, Sonke $P$ : Reversal by the calcium antagonist nisoldipine of norepinephrine-induced reduction of GFR: Evidence for preferential antagonism of preglomerular vasoconstriction. J Pharmacol Exp Ther 1984;232:382-387.

30 Roy M, Guthrie GP, Holladay FP, Kotchen TA: Effects of verapamil on renin and aldosterone in the dog and rat. Am J Physiol 1983;245: E410-E416.

31 Abe Y, Okahara T, Yamamoto K: Effects of D-3-acetoxy-2,3-dihydro-5,2-(dimethylamine) ethyl-2 -(P-methoxyphenyl) -1,5-benzothiazepin- $4(5 \mathrm{H})$-one-hydrochloride (CRD) on renal function in the dig. Jpn Circ J 1972;36:10021003.

32 Johns EJ: The influence of diltiazem and nifedipine on renal function in the rat. Br J Pharmacol 1985;84:707-713.

33 Sunderrajan S, Reams G, Bauer JH: Renal effects of diltiazem in primary hypertension. Hypertension 1986;8:238-242.

34 Loutzenhiser R, Horton C, Epstein M: Effects of diltiazem and manganese on renal hemodynamics: Studies in the isolated perfused rat kidney. Nephron 1985;39:382-388.

35 Loutzenhiser R, Epstein M, Fischetti F, Horton $\mathrm{C}$ : Effects of amlodipine on renal hemodynamics. Am J Cardiol 1989;64:122I-127I.

36 Takabatake T, Ohta H, Sasaki T, Satoh S, Ohta K, Ise T, Kobayashi K: Renal effects of manidipine hydrochloride: A new calcium antagonist in hypertensive patients. Eur J Clin Pharmacol 1993;45:321-325.

37 Takakura S, Furuichi Y, Yamamoto T, Ogawa $\mathrm{T}$, Satoh H, Mori J: Effects of nilvadipine on the development of neurological deficits in stroke-prone spontaneously hypertensive rats. Stroke 1994;25:677-682.

38 Yokoyama T, Masuda Y, Sakai T, Tanaka S, Tomita K: Effects of NZ-105, a new calcium antagonist, on renal function in anesthetized spontaneously hypertensive rats. J Cardiovasc Pharmacol 1992;19:851-856.

39 Loutzenhiser R, Epstein M: Modification of the renal hemodynamic response to vasoconstrictors by calcium antagonists. Am J Nephrol 1987;7(suppl 1):7-16.

40 Loutzenhiser R, Epstein M, Horton C, Sonke $\mathrm{P}$ : Reversal by the calcium antagonist nisoldipine of norepinephrine-induced reduction of GFR: Evidence for preferential antagonism of preglomerular vasoconstriction. J Pharmacol Exp Ther 1985;232:382-387.
41 Allison N, Dubb J, Alexander P, Bodenheimer S, Familiar R, Blumberg A, Stote R: Effect of nilvadipine on renal function in normal man (abstract). Fed Proc 1985;44:1638.

42 Kimura G, Deguchi F, Kojima S, Ashida T, Yoshimi H, Abe H, Kawano Y, Yoshida K, Kawamura M, Imanishi M: Effect of a calciumentry blocker, nicardipine, on intrarenal hemodynamics in essential hypertension. Am J Kidney Dis 1991;18:47-54.

43 Edwards RM: Segmental effects of norepinephrine and angiotensin II on isolated renal microvessels. Am J Physiol 1983;244:F526-F534.

44 Yuan B, Robinette JB, Conger JD: Effects of angiotensin II and norepinephrine on isolated rat afferent and efferent arterioles. Am J Physiol 1990;258:F741-F750.

45 Ito S, Carretero OA: An in vitro approach to the study of macula densa-mediated glomerular hemodynamics. Kidney Int 1990;38:12061210.

46 Ito S, Ren Y: Evidence for the role of nitric oxide in macula densa control of glomerular hemodynamics. J Clin Invest 1993;92:10931098.

47 Casellas D, Navar LG: In vitro perfusion of juxtamedullary nephrons in rats. Am J Physiol 1984;246:F349-F358.

48 Steinhausen M, Snoei H, Parekh N, Baker R, Johnson PC: Hydronephrosis: A new method to visualize vas afferens, efferens, and glomerular network. Kidney Int 1983;23:794-806.

49 Loutzenhiser R, Hayashi K, Epstein M: A trial natriuretic peptide reverses afferent arteriolar vasoconstriction and potentiates efferent arteriolar vasoconstriction in the isolated perfused rat kidney. J Pharmacol Exp Ther 1988;246: 522-528.

50 Yamamoto T, Hayashi K, Matsuda H, Kubota E, Tanaka H, Ogasawara Y, Nakamoto H, Suzuki H, Saruta T, Kajiya F: In vivo visualization of tubuloglomerular feedback- and angiotensin II-induced renal vasoconstriction in dogs by an intravital pencil lens-probe videomicroscope. Kidney Int 2001;60:364-369.

51 Loutzenhiser R, Hayashi K, Epstein M: Divergent effects of $\mathrm{KCl}$-induced depolarization on afferent and efferent arterioles. Am J Physiol 1989;257:F561-F564.

52 Bührle CP, Nobiling R, Taugner R: Intracellular recordings from renin-positive cells of the afferent glomerular arteriole. Am J Physiol 1985;249:F272-F281.

53 Carmines PK, Fower BC, Bell PD: Segmental distinct effects of depolarization on intracellular $\left[\mathrm{Ca}^{2+}\right]$ in renal arterioles. Am J Physiol 1993;265:F677-F685.

54 Steinhausen M, Baehr M: Vasomotion and vasoconstriction induced by a $\mathrm{Ca}$ agonist in the split hydronephrotic kidney. Prog Appl Microcirc 1989;14:25-29.

55 Hansen PB, Jensen BL, Andreasen D, Skøtt O: Differential expression of T- and L-type voltage-dependent calcium channels in renal resistance vessels. Circ Res 2001;89:630-638.
56 Morikawa T, Okumura M, Konishi Y, Okada $\mathrm{N}$, Imanishi M: Effects of benidipine on glomerular hemodynamics and proteinuria in patients with nondiabetic nephropathy. Hypertens Res 2002;25:571-576.

57 Zhou X, Ono H, Ono Y, Frohlich ED: N- and L-type calcium channel antagonist improves glomerular dynamics, reverses severe nephrosclerosis, and inhibits apoptosis and proliferation in an L-NAME/SHR model. J Hypertens 2002;20:993-1000.

58 Yamamoto T, Hayashi K, Matsuda H, Tomura H, Ogasawara Y, Hashimoto R, Tada T, Tanaka $\mathrm{H}$, Kajiya F: Direct in vivo visualization of glomerular microcirculation by intravital pencil lens-probe CCD videomicroscopy. Clin $\mathrm{He}-$ morheol Microcirc 2000;23:103-108.

59 Yamamoto T, Hayashi K, Tomura Y, Tanaka $\mathrm{H}$, Kajiya $\mathrm{F}$ : Direct in vivo visualization of renal microcirculation by intravital CCD videomicroscopy. Exp Nephrol 2001;9:150-155.

60 Matsuda H, Hayashi K, Arakawa K, Kubota E, Honda M, Naito M, Matsumoto A, Suzuki H, Yamamoto T, Kajiya F, Saruta T: Zonal heterogeneity in action of angiotensin-converting enzyme inhibitor on renal microcirculation: Role of intrarenal bradykinin. J Am Soc Nephrol 1999;10:2272-2282.

61 Honda M, Hayashi K, Matsuda H, Kubota E, Tokuyama H, Okubo K, Takamatsu I, Ozawa Y, Saruta T: Divergent renal vasodilator action of L- and T-type calcium antagonists in vivo. $\mathrm{J}$ Hypertens 2001;19:2031-2037.

62 Tokuyama H, Hayashi K, Matsuda H, Kubota E, Honda M, Okubo K, Takamatsu I, Tatematsu S, Ozawa Y, Wakino S, Saruta T: Differential regulation of elevated renal angiotensin II in chronic renal ischemia. Hypertension 2002;40:34-40.

63 Honda M, Hayashi K, Matsuda H, Kubota E, Tokuyama H, Okubo K, Ozawa Y, Saruta T: Divergent natriuretic action of calcium channel antagonists in mongrel dogs: Renal hemodynamics as a determinant of natriuresis. Clin Sci 2001;101:421-427.

64 Hayashi K, Ozawa Y, Saruta T, Epstein M: Renal hemodynamic effects of calcium antagonists; in Epstein M (ed): Calcium Antagonists in Clinical Medicine, ed 3. New York, Hanley \& Belfus, 2001, pp 559-578.

65 Sabbatini M, Leonardi A, Testa R, Vitaioli L, Amenta F: Effect of calcium antagonists on glomerular arterioles in spontaneously hypertensive rats. Hypertension 2000;35:775-779.

66 Ozawa Y, Hayashi K, Oka K, Nagahama T, Saruta T: Divergent action of calcium antagonists on the efferent arteriole (abstract). J Hypertens 1998;16(suppl 2):S27.

67 Masumiya H, Shijuku T, Tanaka H, Shigenobu $\mathrm{K}$ : Inhibition of myocardial L- and T-type $\mathrm{Ca}^{2+}$ currents by efonidipine: Possible mechanism for chronotropic effect. Eur J Pharmacol 1998; 349:351-357.

68 Ertel SI, Ertel EA, Clozel J-P: T-type $\mathrm{Ca}^{2+}$ channels and pharmacological blockade: Potential pathophysiological relevance. Cardiovasc Drugs Ther 1997;11:723-739. 
69 Gustafsson F, Andreasen D, Salomonsson M, Jensen BL, Holstein-Rathlou N-H: Conducted vasoconstriction in rat mesenteric arterioles: role for dihydropyridine-insensitive $\mathrm{Ca}^{2+}$ channels. Am J Physiol 2001;280:H582-H590.

70 Vanbavel E, Sorop O, Andreasen D, Pfaffendorf M, Jensen BL: Role of T-type calcium channels in myogenic tone of skeletal muscle resistance arteries. Am J Physiol 2002;283: H2239-H2243.

71 Nakamura Y, Ono H, Frohlich ED: Differential effects of T- and L-type calcium antagonists on glomerular dynamics in spontaneously hypertensive rats. Hypertension 1999;34:273278.

72 Ishibashi H, Murai Y, Akaike N: Effect of nilvadipine on the voltage-dependent $\mathrm{Ca}^{2+}$ channels in rat hippocampal CA1 pyramidal neurons. Brain Res 1998;813:121-127.

73 Masumiya H, Tanaka Y, Tanaka H, Shigenobu $\mathrm{K}$ : Inhibition of T-type and L- and T-type $\mathrm{Ca}^{2+}$ currents by aranidipine, a novel dihydropyridine $\mathrm{Ca}^{2+}$ antagonist. Pharmacology 2000;61: 57-61.

74 Takenaka T, Suzuki H, Kanno Y, Fujiwara K, Hayashi K, Nagahama T, Saruta T: Cellular mechanisms mediating rat renal microvascular constriction by angiotensin II. J Clin Invest 1997;100:2107-2114.

75 Nagahama T, Hayashi K, Ozawa Y, Takenaka $\mathrm{T}$, Saruta T: Role of protein kinase $\mathrm{C}$ in angiotensin II-induced constriction of renal microvasculature. Kidney Int 2000;57:215-223.

76 Hermsmeyer K, Miyagawa K: Protein kinase C mechanism enhances vascular muscle relaxation by the $\mathrm{Ca}^{2+}$ antagonist, Ro 40-5967. J Vasc Res 1996;33:71-77.

77 Sipido KR, Carmeliet E, Van de Werf F: T-type $\mathrm{Ca}^{2+}$ release from the sarcoplasmic reticulum in guinea-pig ventricular myocytes. J Physiol 1998;508:439-451.

78 Hayashi K, Ozawa Y, Wakino S, Kanda T, Homma K, Yoshioka K, Takamatsu I, Tatematsu S, Saruta T: Cellular Mechanism for mibefradil-induced vasodilation of renal microcirculation-studies in the isolated perfused hydronephrotic kidney. J Cardiovasc Pharmacol 2003, in press.

79 Krautwurst D, Hescheler J, Arndts D, Losel W, Hammer R, Schultz G: Novel potent inhibitor of receptor-activated nonselective cation currents in HL-60 cells. Mol Pharmacol 1994;43: 655-659.

80 Putney JW Jr: 'Kissin' cousins': Intimate plasma membrane-ER interactions underlie capacitative calcium entry. Cell 1999;99:5-8.

81 Wagner C, Krämer KB, Hinder M, Kieninger M, Kurtz A: T-type and L-type calcium channel blockers exert opposite effects on renin secretion and renin gene expression in conscious rats. $\mathrm{Br} \mathrm{J}$ Pharmacol 1998;124:579_ 585.

82 Morimoto S, Takeda K, Oguni A, Kido H, Harada S, Moriguchi J, Itoh H, Nakata T, Sasaki S, Nakagawa M: Reduction of white coat effect by cilnidipine in essential hypertension. Am J Hypertens 2001;14:1053-1057.
83 Takahara A, Dohmoto H, Hisa H, Satoh S, Yoshimoto R: Cilnidipine attenuates renal nerve stimulation-induced renal vasoconstriction and antinatriuresis in anesthetized dogs. Jpn J Pharmacol 1997;75:27-32.

84 Yuasa S, Li X, Hitomi H, Hashimoto M, Fujioka H, Kiyomoto H, Uchida K, Shoji T, Takahashi N, Miki S, Miyatake A, Mizushige K, Matsuo H: Sodium sensitivity and sympathetic nervous system in hypertension induced by long-term nitric oxide blockade in rats. Clin Exp Pharmacol Physiol 2000;27:18-24.

85 Furukawa T, Nukada T, Suzuki K, Fujita Y, Mori Y, Nishimura M, Yamanaka M: Voltage and $\mathrm{pH}$ dependent block of cloned $\mathrm{N}$-type $\mathrm{Ca}^{2+}$ channels by amlodipine. Br J Pharmacol 1997; 121:1136-1140.

86 Kimura K, Suzuki N, Ohba S, Mise N, Miyashita K, Tojo A, Goto A, Omata M: Effects of amlodipine, a calcium channel blocker, on rat renal arterioles. Ther Res 1997;58:375-380.

87 Anderson S, Rennke HG, Brenner BM: Nifedipine versus fosinopril in uninephrectomized diabetic rats. Kidney Int 1992;41:891-897.

88 Brown SA, Walton CL, Crawford P, Bakris G: Long-term effects of antihypertensive regimens on renal hemodynamics and proteinuria. Kidney Int 1993;43:1210-1218.

89 Dworkin LD, Tolbert E, Recht PA, Hersch JC, Feiner H, Levin RI: Effects of amlodipine on glomerular filtration, growth, and injury in experimental hypertension. Hypertension 1996; 27:245-250.

90 Hayashi K, Epstein M, Loutzenhiser R: Pressure-induced vasoconstriction of renal microvessels in normotensive and hypertensive rats: Studies in the isolated perfused hydronephrotic kidney. Circ Res 1989;65:1475-1484.

91 Takenaka T, Suzuki H, Okada H, Hayashi K, Kanno Y, Saruta T: Mechanosensitive cation channels mediate afferent arteriolar myogenic constriction in the isolated rat kidney. J Physiol 1998;511:245-253.

92 Tarif N, Bakris GL: Preservation of renal function: The spectrum of effects by calcium-channel blockers. Nephrol Dial Transplant 1997;12: 2244-2250.

93 Yoshioka T, Shiraga H, Yoshida Y, Fogo A, Glick AD, Deen WM, Hoyer JR, Ichikawa I: 'Intact nephrons' as the primary origin of proteinuria in chronic renal disease: Study in the rat model of subtotal nephrectomy. J Clin Invest 1988;82:1614-1623.

94 Harris DC, Hammond WS, Burke TJ, Schrier RW: Verapamil protects against progression of experimental chronic renal disease. Kidney Int 1987;31:41-46.

95 Dworkin LD, Feiner HD, Parker M, Tolbert E: Effects of nifedipine and enalapril on glomerular structure and function in uninephrectomized SHR. Kidney Int 1991;9:1112-1117.

96 Dworkin LD, Levin RI, Benstein JA, Parker M, Ullian ME, Kim Y, Feiner HD: Effects of nifedipine and enalapril on glomerular injury in rats with deoxycorticosterone-salt hypertension. Am J Physiol 1990;259:F598-F604.
97 Wenzel UO, Troschau G, Schoeppe W, Helmchen U, Schwietzer G: Adverse effect of the calcium channel blocker nitrendipine on nephrosclerosis in rats with renovascular hypertension. Hypertension 1992;20:233-241.

98 Pelayo JC, Westoo JY: Impaired autoregulation of glomerular capillary hydrostatic pressure in the rat remnant nephron. J Clin Invest 1991;88:101-105.

99 Shudo C, Masuda Y, Sugita H, Furukawa S, Hayashi K, Hirata H, Tanaka S, Tomita K: Renal protective effect of efonidipine hydrochloride (NZ-105), a new calcium antagonist, in spontaneously hypertensive rats. Gen Pharmacol 1994;25:1567-1575.

100 Shudo C, Masuda Y, Sugita H, et al: Beneficial effect of efonidipine hydrochloride (NZ105) on proteinuria in aged spontaneously hypertensive rats (SHR). Pharm Sci 1995;1: 333-335.

101 Shudo C, Masuda Y, Sugita H, Tamura T, Furukawa S, Hayashi K, Hirata H, Shikada K, Tanaka S, Tomita K: Effects of efonidipine, nicardipine and captopril on proteinuria in aged spontaneously hypertensive rats. Arzneimittel-Forsch 1996;46:852-854.

102 Fujimaki M, Nagase M, Uchida S: Long-term effect of manidipine on renal function and structure in uninephrectomized spontaneously hypertensive rats. Clin Exp Pharmacol Physiol 1997;24:506-512.

103 Karam H, Clozel J-P, Bruneval P, Gonzalez M-F, Ménard J: Contrasting effects of selective T- an L-type calcium channel blockade on glomerular damage in DOCA hypertensive rats. Hypertension 1999;34:673-678.

104 Griffin K, Picken M, Bakris GL, Bidani AK: Comparative effects of selective T- and Ltype calcium channel blockers in the remnant kidney model. Hypertension 2001;37:12681272.

105 Katsumata H, Suzuki H, Ohishi A, Nakamoto H, Saruta T, Sakaguchi H: Effects of antihypertensive agents on blood pressure and the progress of renal failure in partially nephrectomized spontaneously hypertensive rats. Lab Invest 1990;62:474-480.

106 Kanno Y, Suzuki H, Okada H, Saruta T: Renal protective effects of amlodipine on partially nephrectomized spontaneously hypertensive rats fed a high-salt diet. J Cardiovasc Pharmacol 1994;23:480-484.

107 Fujiwara K, Hayashi K, Kanno Y, Takenaka $\mathrm{T}$, Saruta T: Renal protective effects of efonidipine hydrochloride in subtotally nephrectomized spontaneously hypertensive rats. Clin Exp Hypertens 1998;23:295-312.

108 Nagahama T, Hayashi K, Fujiwara K, Ozawa Y, Saruta T: Characterization of renal action of pranidipine in the rat. Arzneimittel-Forsch 2000;50:248-253.

109 Hostetter TH, Olson JL, Rennke HG, Venkatachalam MA, Brenner BM: Hyperfiltration in remnant nephrons: A potentially adverse response to renal ablation. Am J Physiol 1981;241:F85-F93. 
110 Sweeney C, Shultz P, Raij L: Interactions of the endothelium and mesangium in glomerular injury. J Am Soc Nephrol 1990;1:S13S20

111 Raij L, Keane W: Glomerular mesangium: Its function and relationship to angiotensin II. Am J Med 1985;79(suppl 36):24-30.

112 Sugiura T, Imai E, Moriyama T, Horio M, Hori M: Calcium channel blockers inhibit proliferation and matrix production in rat mesangial cells: Possible mechanism of suppression of AP-1 and CREB activities. Nephron 2000;85:71-80.

113 Ono T, Liu N, Kusano H, Nogaki F, Makino T, Muso E, Sasayama S: Broad antiproliferative effects of benidipine on cultured human mesangial cells in cell cycle phases. Am J Nephrol 2002;22:581-586.

114 Roth M, Keul R, Emmons LR, Horl WH, Block LH: Manidipine regulates the transcription of cytokine genes. Proc Natl Acad Sci USA 1992;89:4071-4075.
115 Hayashi M, Yamaji Y, Nakazato Y, Saruta T: The effects of calcium channel blockers on nuclear factor kappa B activation in the mesangial cells. Hypertens Res 2000;23:521525.

116 Fukuo K, Yang J, Yasuda O, Mogi M, Suhara T, Sato N, Suzuki T, Morimoto S, Ogihara T: Nifedipine indirectly upregulates superoxide dismutase expression in endothelial cells via vascular smooth muscle cell-dependent pathways. Circulation 2002;106:356-361.

117 Chen L, Haught WH, Yang B, Saldeen TG, Parathasarathy S, Mehta JL: Preservation of endogenous antioxidant activity and inhibition of lipid peroxidation as common mechanisms of anti-atherosclerotic effects of vitamin E, lovastatin and amlodipine. J Am Coll Cardiol 1997;30:569-575.

118 Hayashi K, Kumagai H, Saruta T: Effects of efonidipine and ACE inhibitors on proteinuria in human hypertension with renal impairment. Am J Hypertens 2003;16:116122.
119 Agodoa LY, Appel L, Bakris GL, Beck G, Bourgoignie J, Briggs JP, Charleston J, Cheek D, Cleveland W, Douglas JG, Douglas M, Dowie D, Faulkner M, Gabriel A, Gassman J, Greene T, Hall Y, Hebert L, Hiremath L, Jamerson K, Johnson CJ, Kopple J, Kusek J, Lash J, Lea J, Lewis JB, Lipkowitz M, Massry S, Middleton J, Miller ER 3rd, Norris K, O'Connor D, Ojo A, Phillips RA, Pogue V, Rahman M, Randall OS, Rostand S, Schulman G, Smith W, Thornley-Brown D, Tisher CC, Toto RD, Wright JT Jr, Xu S; African American Study of Kidney Disease and Hypertension (AASK) Study Group: Effect of ramipril vs. amlodipine on renal outcomes in hypertensive nephrosclerosis: A randomized controlled trial. JAMA 2002;285:2719-2728.

120 The ALLHAT Officers and Coordinators for the ALLHAT Collaborative Research Group: Major outcomes in high-risk hypertensive patients randomized to angiotensin-converting enzyme inhibitor or calcium channel blocker vs. diuretics. JAMA 2003;288:2981-2997. 